\title{
Tailoring of evidence-based group intervention with children with disruptive behavior: Implications for therapists and researchers
}

\author{
John E. Lochman'
}

University of Alabama, Tuscaloosa, Alabama, EE. UU.

\section{Correspondence:}

John E. Lochman

University of Alabama, Tuscaloosa,

Alabama, EE. UU.

276A Gordon Palmer

Phone: (205) 246-1236

Email:॥lochman@ua.edu

\section{Citation:}

Lochman, J. E. (202 1). Tailoring of evidence-based group intervention with children with disruptive behavior: Implications for therapists and researchers. Salud Mental, 44(6), 257-260.

DOI: $10.17711 /$ SM.0185-3325.2021.033

\section{(c) (i) (8)}

The evidence-bas for cognitive-behavioral child interventions has continued to advance in the past several decades across many areas of psychopathology, including disruptive behavior problems. We know quite a bit about what works. However, despite earlier research efforts (e.g., Copeland \& Hammel, 1981; Lochman, Lampron, Burch, \& Curry, 1985; Conduct Problems Prevention Research Group, 2002), we are still in early stages of understanding "what works for whom." Efforts to explore moderators of established interventions, rather than merely efficacy (La Greca, Silverman, \& Lochman, 2009), can progressively help to identify how we can tailor interventions for different children, and tailor training for therapists. One example occurs in research efforts to clarify whether group-based interventions might have iatrogenic effects with some children with disruptive behavior problems.

Reviews of group-based intervention research have found group treatment to be generally effective in reducing youths' conduct problems and substance use (e.g., Vaughn \& Howard, 2004; Weiss et al., 2005). The Coping Power program is one such group-based program that has produced reductions in disruptive behavior problems in randomized control studies at post-intervention and through one-to-four year followups after intervention (Cabiya et al., 2008; Lochman et al., 2014; Lochman \& Wells, 2003; 2004; Lochman, Wells, Qu, \& Chen, 2013; Muratori et al., 2017a; Mushtaq, Lochman, Tariq, \& Sabih, 2017; Zonnevylle-Bender, Matthys, van de Wiel, \& Lochman, 2007). However, it is important to consider possible iatrogenic effects when providing an intervention targeting disruptive behavior in a group delivery format because of concerns about deviancy training (peer reinforcement of children's deviant talk and behavior; Dishion, Poulin, \& Burraston, 2001). A warning about potential iatrogenic effects was clearly evident in a study by Dishion and Andrews (1995) in which children in a cognitive-behavioral intervention actually had more problem behaviors than did untreated control children at follow-ups one and three years after intervention (Poulin, Dishion, \& Burraston, 2001).

Because the Coping Power program has typically been delivered in small groups, a large-scale study was conducted to investigate how children fare if they received Coping Power in a group versus individual format (Lochman et al., 2015a). Results indicated both intervention delivery methods led to similar significant reductions in parent-rated externalizing problems through a one-year follow-up period. However, although teacher-rated externalizing problems also declined significantly for both intervention conditions, the reductions were significantly greater for children receiving Coping Power in an individual format. This main effect was moderated by children's baseline levels of inhibitory control. Children with fewer problems with inhibitory control responded in similar positive ways to either the group or individual format, but children with weak inhibitory control benefited more from being seen in one-to-one sessions. Similar findings were evident in a longer-term follow-up through eleventh grade, with youth with weakest inhibitory control prior to intervention having slower increases in substance use if they were seen individually rather than in groups (Lochman et al., 2021). However, youth with stronger inhibitory 
control had better substance use outcomes if they were randomized to the group format, indicating the strong benefits of groups as well.

Other studies with this sample found that children receiving the group intervention who were less prone to social reward (A/A genotype of oxytocin receptor gene SNP rs2268493; Glenn et al., 2018), and had better emotional regulation (respiratory sinus arrhythmia; Glenn et al., 2019) had better teacher-rated outcomes than their peers. At a later four-year follow-up (Lochman et al., 2019), results confirm and extend the pattern of prior findings, indicating that several of these classes of characteristics (oxytocin receptor genotype; skin conductance [SCL] reactivity) continue to predict outcomes years later when the youth have moved into high school. Aggressive children who have very strong social orientations, such as children with the G/G genotype, may have been more over-involved with peers in the group condition, and thus less able to deeply incorporate and internalize the social-cognitive regulation skills being discussed and practiced. Similarly, when seen individually, aggressive children who have hypersensitive stress responses, evident in their autonomic nervous system over-reactivity, may be better able to understand and practice the intervention's methods for emotional regulation in the safe context of their therapeutic relationship with their therapist in comparison to similar children assigned to group intervention.

Group therapists' clinical skills also emerged as important predictors of outcomes in this long-term follow-up study (Lochman et al., 2019). The clinical skills construct included ratings for not appearing frustrated, angry or irritable, having a warm and positive tone of voice with students, acting in a mature and professional way (e.g., appropriate level of self-disclosure), and not being overly rigid with the implementation of the manualized intervention activities. Leaders with high levels of clinical skills had children who had the most reduced slopes of teacher-rated externalizing problems over time. Clinical skills were perhaps surprisingly more important in predicting outcome than were group leaders' behavioral management and "teaching" styles (Lochman, Dishion, Boxmeyer, Powell, \& Qu, 2017).

There are at least three ways in which clinical skills, as measured here, can influence children's outcomes (Lochman et al., 2017). First, group therapists who handle difficult interpersonal provocations from their child clients by exerting inhibitory control over their own expression of their own frustration and by effectively regulating their arousal are modeling key processes which can be instrumental for children learning to improve their own emotional regulation over time (Chapman, Baker, Porter, Thayer, \& Burlingame, 2010; Stewart, Christner, \& Freeman, 2007). Second, group leaders who respond more frequently in warm ways to the children in their groups are likely providing more social reinforcement for positive child behaviors within the sessions (Follette, Naugle, \& Callaghan, 1996), and facil- itating sustained generalized reductions in problem behaviors outside of the group sessions. Third, in a related way, group leaders who respond to children with more warmth are likely to develop stronger therapeutic alliances with the children, and the children can become more engaged with the intervention. Children who have become well-engaged in the Coping Power intervention by the middle sessions of the program have been found to have greater reductions in externalizing behavior by post-intervention (Lindsey et al., 2019). Children who are more engaged in the intervention may learn the social-emotional skills more deeply.

Several key implications emerge from this set of studies. First, carefully-structured evidence-based group interventions can be acceptable, and in some cases even preferable, for most children with histories of disruptive behaviors. Second, a small subset of children with disruptive behaviors could make more enduring gains from being seen in individual intervention rather than in groups, and these children can be characterized as having unusually poor inhibitory control, excessive desire for social bonding with peers, and extreme emotional dysregulation. Third, group therapists should receive intensive training for leading groups. In addition to providing group therapists with precise skills in how to monitor and provide consequences for children's behavior in the groups, these findings demonstrate that therapists' clinical skills, as rated during group sessions, predict children's externalizing behaviors during the years after the program has been completed. The simple story is that group therapists who are positive and professional in their interactions with their group children, and who are less angry-irritable with them, have children who exhibit greater reductions in externalizing behavior problems over time. In a sense, the clinicians' behavior may provide a protective effect for children who are in a group intervention that carries certain risk for deviant peer interactions and escalating group emotional and behavioral contagion.

Therapists' own emotional regulation, their use of social reinforcement, and their ability to stimulate child engagement in sessions can all contribute to optimal outcomes from group intervention (Lochman et al., 2017). In a related way, in a separate study, we have found that therapists who have more agreeable personality traits can implement Coping Power with greater quality of implementation and tend to be more likely to sustain their use of the program over time (Lochman et al., 2009; 2015b). Therapists with an agreeable personality trait may find it easier to respond in relatively automatic, flexible, self-regulated ways, and to thus implement a group cognitive-behavioral intervention in qualitatively better ways (Lochman et al., 2009). In another closely related study, Muratori et al. (2017b) found that therapists who had an anxious, preoccupied attachment style had child clients, who had received Coping Power group intervention in community hospitals, who increased in their aggression over time, in contrast to children who 
had received Coping Power from therapists who had a secure attachment style. A therapist with an anxious attachment style that involves excessive preoccupation with relationships may tend to intervene anxiously with a difficult child in their group, modeling poor regulation of their own arousal.

We anticipate that the behavioral expression of these capacities can, and should, be addressed and included in intensive training for group therapists. Some group leaders would likely have to learn to use more deliberate strategies to monitor their own arousal in sessions and to purposefully use cognitive and physiological regulation strategies. Thus, the training of group leaders should emphasize not only skill-training in a traditional sense, but also focus on how group leaders can practice emotional regulation themselves while engaged in group work that can be inherently stressful and frustrating at times. It is clinically and ethically imperative for group therapists to obtain rigorous, evidence-based training, and performance feedback.

\section{REFERENCES}

Cabiya, J. J., Padilla-Cotto, L., González, K., Sanchez-Cestero, J., Martínez-Taboas, A., \& Sayers, S. (2008). Effectiveness of a cognitive-behavioral intervention for Puerto Rican children. Interamerican Journal of Psychology, 42(2), 195-202.

Chapman, C. L., Baker, E. L., Porter, G., Thayer, S. D., \& Burlingame, G. M. (2010). Rating group therapist interventions: The validation of the Group Psychotherapy Intervention Rating Scale. Group Dynamics: Theory, Research, and Practice, 14(1), 15-31. doi: 10.1037/a0016628

Conduct Problems Prevention Research Group. (2002). Predictor variables associated with positive Fast Track outcomes at the end of third grade. Journal of Abnormal Child Psychology, 30(1), 37-52.

Copeland, A. P., \& Hammel, R. (1981). Subject variables in cognitive selfinstructional training. Cognitive Therapy and Research, 5(4), 405-420. doi: 10.1007/BF01173692

Dishion, T. J., \& Andrews, D. W. (1995). Preventing escalation in problem behaviors with high-risk young adolescents: immediate and 1-year outcomes. Journal of Consulting and Clinical Psychology, 63(4), 538-548. doi: 10.1037/0022006X.63.4.538

Dishion, T. J., Poulin, F., \& Burraston, B. (2001). Peer group dynamics associated with iatrogenic effect in group interventions with high-risk young adolescents. New Directions for Child and Adolescent Development, (91), 79-92. doi: 10.1002/cd.6

Follette, W. C., Naugle, A. E., \& Callaghan, G. M. (1996). A radical behavioral understanding of the therapeutic relationship in effecting change. Behavior Therapy, 27(4), 623-641. doi: 10.1016/S0005-7894(96)80047-5

Glenn, A. L., Lochman, J. E., Dishion, T., Powell, N. P., Boxmeyer, C., \& Qu, L. (2018). Oxytocin receptor gene variant interacts with intervention delivery format in predicting intervention outcomes for youth with conduct problems. Prevention Science, 19(1), 38-48. doi: 10.1007/s11121- 017-0777-1

Glenn, A. L., Lochman, J. E., Dishion, T., Powell, N. P., Boxmeyer, C., Kassing, F., ... Romero, D. (2019). Toward tailored interventions: Sympathetic and parasympathetic functioning predicts responses to an intervention for conduct problems delivered in two formats. Prevention Science, 20(1), 30-40. doi: 10.1007/s11121-017-0859-0

La Greca, A. M., Silverman, W. K., \& Lochman, J. E. (2009). Moving beyond efficacy and effectiveness in child and adolescent intervention research. Journal of Consulting and Clinical Psychology, 77(3), 373-382. doi: 10.1037/a0015954

Lindsey, M. A., Romanelli, M., Ellis, M. L., Barker, E. D., Boxmeyer, C. L., \& Lochman, J. E. (2019). The influence of treatment engagement on positive outcomes in the context of a school-based intervention for students with externalizing behavior problems. Journal of Abnormal Child Psychology, 47(9), 1437-1454. doi: 10.1007/s10802-019-00525-6

Lochman, J. E., \& Wells, K. C. (2003). Effectiveness of the coping power program and of classroom intervention with aggressive children: Outcomes at a 1-year follow-up. Behavior Therapy, 34, 493-515. doi: 10.1016/S00057894(03)80032-1

Lochman, J. E., \& Wells, K. C. (2004). The coping power program for preadolescent aggressive boys and their parents: Outcome effects at the 1-year followup. Journal of Consulting \& Clinical Psychology, 72(4), 571-578. doi: 10.1037/0022-006X.72.4.571

Lochman, J. E., Baden, R. E., Boxmeyer, C. L., Powell, N. P., Qu, L., Salekin, K. L., \& Windle, M. (2014). Does a booster intervention augment the preventive effects of an abbreviated version of the coping power program for aggressive children? Journal of Abnormal Child Psychology, 42(3), 367-381. doi: 10.1007/ s10802-013-9727-y

Lochman, J. E., Boxmeyer, C. L., Bui, C., Hakim, E., Jones, S., Kassing, F., ... Dishion, T. (2021). Substance use outcomes from two formats of a cognitivebehavioral intervention for aggressive children: moderating roles of inhibitory control and intervention engagement. Brain Sciences, 11(7), 950. doi: 10.3390/ brainsci11070950

Lochman, J. E., Dishion, T. J., Boxmeyer, C. L., Powell, N. P., \& Qu, L. (2017). Variation in response to evidence-based group preventive intervention for disruptive behavior problems: A view from 938 coping power sessions. Journal of Abnormal Child Psychology, 45(7), 1271-1284. doi: 10.1007/s10802-0160252-7

Lochman, J. E., Dishion, T. J., Powell, N. P., Boxmeyer, C. L., Qu, L., \& Sallee, M. (2015a). Evidence-based preventive intervention for preadolescent aggressive children: One-year outcomes following randomization to group versus individual delivery. Journal of Consulting and Clinical Psychology, 83(4), 728735. doi: 10.1037/ccp0000030

Lochman, J. E., Glenn, A. L., Powell, N. P., Boxmeyer, C. L., Bui, C., Kassing, F., ... Dishion, T. (2019). Group versus individual format of intervention for aggressive children: Moderators and predictors of outcomes through four years after intervention. Development and Psychopathology, 31(5), 1757-1775. doi: 10.1017/S0954579419000968

Lochman, J. E., Lampron, L. B., Burch, P. R., \& Curry, J. F. (1985). Client characteristics associated with behavior change for treated and untreated aggressive boys. Journal of Abnormal Child Psychology, 13(4), 527-538. doi: 10.1007/BF00923139

Lochman, J. E., Powell, N. P., Boxmeyer, C. L., Qu, L., Sallee, M., Wells, K. C., \& Windle, M. (2015b). Counselor-level predictors of sustained use of an indicated preventive intervention for aggressive children. Prevention Science, 16(8), 1075-1085. doi: 10.1007/s11121-014-0511-1

Lochman, J. E., Powell, N. P., Boxmeyer, C. L., Qu, L., Wells, K. C., \& Windle, M. (2009). Implementation of a school-based prevention program: Effects of counselor and school characteristics. Professional Psychology: Research and Practice, 40(5), 476-482. doi: 10.1037/a0015013

Lochman, J. E., Wells, K. C., Qu, L., \& Chen, L. (2013). Three year follow-up of Coping Power intervention effects: Evidence of neighborhood moderation? Prevention Science, 14(4), 364-376. doi: 10.1007/s11121-012-0295-0

Muratori, P., Milone, A., Manfredi, A., Polidori, L., Ruglioni, L., Lambruschi, F., ... Lochman, J. E. (2017a). Evaluation of improvement in externalizing behaviors and callous-unemotional traits in children with Disruptive Behavior Disorder: A 1-year follow up clinic-based study. Administration and Policy in Mental Health and Mental Health Services Research, 44(4), 452-462. doi: 10.1007/ s10488-015-0660-y

Muratori, P., Polidori, L., Chiodo, S., Dovigo, V., Mascarucci, M., Milone, A., ... Lochman, J. E. (2017b). A pilot study implementing Coping Power in Italian community hospitals: Effect of therapist attachment style on outcomes in children. Journal of Child and Family Studies, 26(11), 3093-3101. doi: 10.1007/ s10826-017-0820-7

Mushtaq, A., Lochman, J. E., Tariq, P. N., \& Sabih, F. (2017). Preliminary effectiveness study of Coping Power program for aggressive children in Pakistan. Prevention Science, 18(7), 762-771. doi: 10.1007/s11121-016-0721-9 
Poulin, F., Dishion, T. J., \& Burraston, B. (2001). 3-year iatrogenic effects associated with aggregating high-risk adolescents in cognitive-behavioral preventive interventions. Applied Developmental Science, 5(4), 214-224. 10.1207/ S1532480XADS0504 03

Stewart, J. L., Christner, R. W., \& Freeman, A. (2007). An introduction to cognitivebehavior group therapy with youth. In R. W. Christner, J. L. Stewart, \& A. Freeman (Eds.). Cognitive-behavior group therapy with children and adolescents (pp. 3-21). New York: Routledge.

Vaughn, M. G., \& Howard, M. O. (2004). Adolescent substance abuse treatment: A synthesis of controlled evaluations. Research in Social Work Practice, 14(5), 325-335. doi: 10.1177/1049731504265834
Weiss, B., Caron, A., Ball, S., Tapp, J., Johnson, M., \& Weisz, J. R. (2005). Iatrogenic effects of group treatment for antisocial youths. Journal of Consulting and Clinical Psychology, 73(6), 1036-1044. doi: 10.1037/0022-006X.73.6.1036

Zonnevylle-Bender, M. J. S., Matthys, W., van de Wiel, N. M. H., \& Lochman, J. E. (2007). Preventive effects of treatment of disruptive behavior disorder in middle childhood on substance use and delinquent behavior. Journal of the American Academy of Child \& Adolescent Psychiatry, 46(1), 33-39. doi: 10.1097/01. chi.0000246051.53297.57 